\title{
Experiment Study on Friction Behaviour of Ti-6Al-4V Alloy for Hot-working
}

\author{
Fan LI, Jia GUO, Wen-Xiang ZHANG, Jun CAO, Yu-Tong LIN, Ce ZHOU and \\ Fu-Guo LI ${ }^{\mathrm{a}, *}$
}

\author{
State Key Laboratory of Solidification Processing, School of Materials Science and Engineering, \\ Northwestern Polytechnical University, Xi'an 710072, China \\ afuguolx@nwpu.edu.cn
}

\begin{abstract}
Keywords: Ti-6Al-4V alloy, Coefficient of friction, Orthogonal test, Friction mechanism, Abrasive wear.
\end{abstract}

\begin{abstract}
The friction behaviour between blank and die plays an important role in the precision forging process. Hence, the friction behaviour between Ti-6Al-4V alloy and K15 is studied to analyse the friction mechanism and characterization. The significant differences and influence law of temperature, sliding velocity and normal load on coefficient of friction (CoF) were studied through orthogonal tests. The range analysis and analysis of variance show that $\mathrm{CoF}$ is affected by normal load most, followed by sliding velocity and temperature. The worn-out appearances and composition analysis show that friction mechanism converts from dry friction to viscous or shear friction under a certain condition.
\end{abstract}

\section{Introduction}

In precision forging process, friction has a significant impact on the lifespan of the mould, the quality of the finished parts and mechanical properties $[1,2]$. For example, in the process of turbine blade forging, friction greatly affects the deformation resistance of sheet and the wear of die [3]. Therefore, it is important to determine the coefficient of friction $(\mathrm{CoF})$ and friction mechanism between the surface of die and workpiece under different friction conditions, which is helpful to improve the forming ability and performance of forging parts.

Friction is a complex and nonlinear phenomenon. From one aspect, $\mathrm{CoF}$ changes complicatedly with the change of friction conditions, such as temperature, sliding velocity and normal load [4]. Molinari et al. [5] showed CoF decreases with the increase of sliding velocity in a certain range for the generation of frictional heating. Johnson et al. [6] showed that $\mathrm{CoF}$ decreases with the increase of temperature. Xing et al. [7] showed that the friction behaviour and mechanism will be more complicated with the simultaneous influence of temperature, normal load and sliding velocity. From another point of view, with the change of these three parameters, friction model, such as dry friction, viscous friction, shear friction and so on, will also change complicatedly. Some scholars try to analyse and describe friction mechanism by different friction models. Friction models so far have been proposed include Coulomb friction model, Stribeck friction model, Karnopp friction model, seven parameters friction model and so on [8]. Meanwhile, friction behaviour and surface morphology have important effects on the research of friction and wear mechanism. Cui et al. [9] researched the wear properties of Ti-6Al-4V alloy, showed that adhesive wear and abrasive wear are mainly occurred at temperature $20-200{ }^{\circ} \mathrm{C}$ and the oxidation wear is obvious when temperature surpasses $400{ }^{\circ} \mathrm{C}$.

Ti-6Al-4V alloy is widely used in aerospace for its high specific strength modulus. However, the deformation ability of Ti-6Al-4V alloy is poor at room temperature, so it is often formed by hotworking. Therefore, the friction mechanism will be more complex. Thus, in this work, according to thermal friction and wear tests, the significant factors affecting $\mathrm{CoF}$ in Ti-6Al-4V alloy were investigated by orthogonal experiments firstly. Then, the influencing rules of various significant 
factors on the $\mathrm{CoF}$ were clarified and discussed. The worn-out appearances and friction mechanism analysis were analysed.

\section{Experiment}

\section{Materials and experimental procedures}

The specimens chosen for the experiments include a flat specimen and a ball specimen. The flat specimens, $4 \mathrm{~mm}$ in thickness, were cut by wire cut electrical discharge machining (WEDM) from Ti-6Al-4V alloy bar with diameter $50 \mathrm{~mm}$. Table 1 shows the chemical composition of Ti-6Al-4V alloy. The ball specimens, $6 \mathrm{~mm}$ in diameter, selected K15 on materials selection.

The surface of flat specimens was polished by 400\#, 600\#, 800\# and 1200\# alumina waterresistant sandpaper successively before tests. Before and after the tests, we used acetone and ethanol to clean the surface successively. Friction and wear test was carried out on GHT-1000E type vacuum atmosphere high temperature friction and wear testing equipment. The main parts of the testing machine and its working principle are shown in Figure 1. The test normal load ranges from 3 to $15 \mathrm{~N}$, the sliding velocity ranges from $14.14 \mathrm{~mm} / \mathrm{s}$ to $900 \mathrm{~mm} / \mathrm{s}$ and the temperature ranges from $323.2 \mathrm{~K}$ to $873.2 \mathrm{~K}$. We used orthogonal test table (shown in Table 2) to complete the multi-factor coupling test. The rising rate of temperature is $100 \mathrm{~K} / \mathrm{min}$. The time of friction is 15 min because the $\mathrm{CoF}$ is basically stable around $15 \mathrm{~min}$.

Table 1. Chemical composition of Ti-6Al-4V alloy (wt. \%).

\begin{tabular}{llllllll}
\hline $\mathrm{Al}$ & $\mathrm{V}$ & $\mathrm{Fe}$ & $\mathrm{C}$ & $\mathrm{H}$ & $\mathrm{O}$ & $\mathrm{N}$ & $\mathrm{Ti}$ \\
\hline 6.09 & 4.19 & 0.22 & 0.015 & 0.002 & 0.17 & 0.002 & Bal. \\
\hline
\end{tabular}

Table 2. Orthogonal table for friction tests of Ti-6Al-4V alloy.

\begin{tabular}{lll|l}
\hline$T(\mathrm{~K})$ & $L(\mathrm{~N})$ & $v(\mathrm{~mm} / \mathrm{s})$ & $\mu$ \\
\hline 323.2 & 3.0 & 14.137 & 0.3960 \\
323.2 & 5.0 & 70.00 & 0.4517 \\
323.2 & 9.0 & 133.00 & 0.3658 \\
323.2 & 12.0 & 350.00 & 0.3126 \\
323.2 & 15.0 & 900.00 & 0.3485 \\
498.2 & 3.0 & 900.00 & 0.3959 \\
498.2 & 5.0 & 14.137 & 0.5021 \\
498.2 & 9.0 & 70.00 & 0.3796 \\
498.2 & 12.0 & 133.00 & 0.3545 \\
498.2 & 15.0 & 350.00 & 0.2126 \\
623.2 & 5.0 & 900.00 & 0.3990 \\
623.2 & 9.0 & 14.137 & 0.2626 \\
623.2 & 3.0 & 350.00 & 0.5217 \\
623.2 & 12.0 & 70.00 & 0.3726 \\
623.2 & 15.0 & 133.00 & 0.4239 \\
723.2 & 3.0 & 133.00 & 0.4725 \\
723.2 & 5.0 & 350.00 & 0.4820 \\
723.2 & 9.0 & 900.00 & 0.3387 \\
723.2 & 12.0 & 14.137 & 0.1536 \\
723.2 & 15.0 & 70.00 & 0.3170 \\
873.2 & 3.0 & 70.00 & 0.4558 \\
873.2 & 5.0 & 133.00 & 0.4929 \\
873.2 & 9.0 & 350.00 & 0.4322 \\
873.2 & 12.0 & 900.00 & 0.4369 \\
873.2 & 15.0 & 14.137 & 0.2909 \\
\hline
\end{tabular}



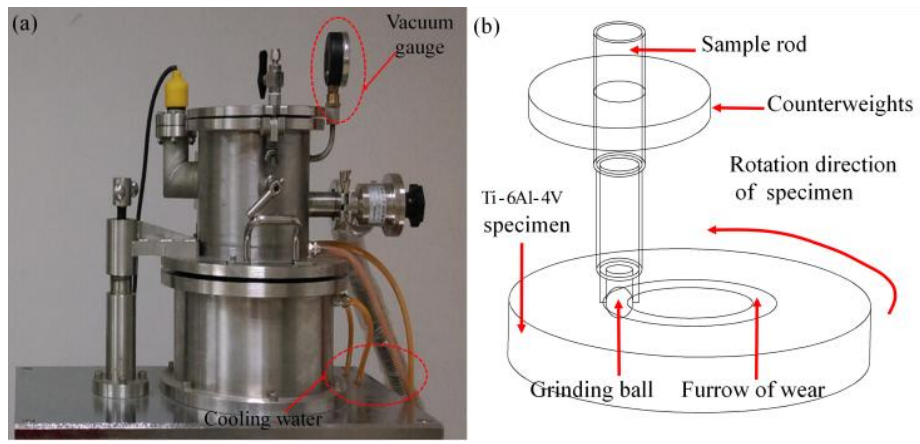

Figure 1. GHT-1000E type vacuum atmosphere high temperature friction and wear testing equipment: (a) main components; (b) schematic diagram of the grinding situation.

The morphology and microstructure of friction surface were observed by VEGA3 LMU TESCAN scanning electron microscope, and the chemical composition of the wear scar was analysed by EDS.

\section{Correction of temperature parameter}

When a ball specimen touches a flat specimen, the contact surface is pressed into a circle. Based on Hertz contact theory, the radius of contact surface, $a$, can be calculated by the following formula:

$$
a=1.11 \sqrt[3]{\frac{P \cdot R}{\mathrm{E}}}
$$

where $R$ is the radius of the grinding ball, $P$ is normal load, $\mathrm{E}$ is the Young's modulus. The maximum compressive stress at the centre of pressure surface, $\sigma_{\max }$, is:

$$
\sigma_{\max }=0.388 \sqrt[3]{\frac{P \cdot \mathrm{E}^{2}}{R^{2}}}
$$

The average normal stress can be got from the maximum compressive stress. During the grinding process, the true normal load of the pressure surface, $P_{\max }$, is:

$$
P_{\max }=\frac{\sigma_{\max } \cdot P I \cdot a^{2}}{4}
$$

where $a$ is the radius of contact surface, $P I$ is the ratio of

circumference. So the friction force between the friction pairs is:

$$
f=\mu \cdot P_{\max }
$$

where $\mu$ is CoF. Ignore the energy loss of the friction system at the moment from static to dynamic. The rising temperature of local friction region was the result of the work caused by friction. The work caused by friction per second is:

$$
W=f \cdot v
$$

where $f$ is the friction force between the friction pairs, $v$ is the sliding velocity. As is known, the heat conductivity of Ti-6Al-4V alloy, $\mathrm{I}$, is $6.7 \mathrm{~W}(\mathrm{~m} \cdot \mathrm{K})^{-1}$ (data from Matweb). Take the local length approximately as $1 \mathrm{~mm}$ during the course of dynamical friction. Therefore, the rising temperature of local friction region, $\Delta T$, is:

$$
\Delta T=\frac{W}{I \cdot L}
$$

where $W$ is the work caused by friction per unit time, $L$ is the local length. The variates got by normalized processing, are used to analyse ODF. 


\section{Results and Discussion}

\section{Significant factors analysis}

In order to determine the significant factors affecting the tribological behaviours of Ti-6Al-4V alloy during hot-working, the orthogonal friction test with three factors and five levels $\left(5^{3}\right)$ was used in this work. Table 2 shows the influencing factors, levels and results of the orthogonal friction test.

Table 3. Range analysis data and results.

\begin{tabular}{llll}
\hline$K$ & $T$ & $L$ & $v$ \\
\hline$k 1$ & 1.8747 & 2.2418 & 1.6053 \\
$k 2$ & 1.8446 & 2.3277 & 1.9767 \\
$k 3$ & 1.9797 & 1.7789 & 2.1095 \\
$k 4$ & 1.7638 & 1.6302 & 1.9611 \\
$k 5$ & 2.1088 & 1.5929 & 1.9190 \\
\hline$\overline{k 1}$ & 0.3749 & 0.4484 & 0.3211 \\
$\overline{k 2}$ & 0.3689 & 0.4655 & 0.3953 \\
$\overline{k 3}$ & 0.3959 & 0.3558 & 0.4219 \\
$\overline{k 4}$ & 0.3528 & 0.3261 & 0.3922 \\
$\overline{k 5}$ & 0.4218 & 0.3186 & 0.3838 \\
\hline$R$ & 0.3450 & 0.7348 & 0.5042 \\
\hline$R^{\prime}$ & 0.0690 & 0.1470 & 0.1008 \\
\hline & & &
\end{tabular}

Based on the experimental results, range analysis method was applied to the orthogonal test. As shown in Table 3, the range values $(R)$ of three factors are as follows: normal load $>$ sliding velocity $>$ temperature. And fluctuations of $K$ are also given in Figure 2(a), 3(a) and 4(a).

Table 4. Analysis of variance (ANOVA) of CoF.

\begin{tabular}{llllll}
\hline Sources & \multicolumn{1}{l}{$S S_{j}$} & $d f_{j}$ & $V_{j}$ & $F_{j}$ & significance \\
\hline$T$ & 0.0142 & 4 & 0.0036 & 0.6995 & Insignificant \\
$L$ & 0.0960 & 4 & 0.0240 & 4.7182 & $* *$ \\
$v$ & 0.0279 & 4 & 0.0070 & 1.3728 & Insignificant \\
$e(\mu)$ & 0.0611 & 12 & 0.0051 & & \\
Total & 0.1993 & 24 & & & \\
\hline $\mathrm{F}_{0.10}(4$, & $12)=2.48$, & $\mathrm{F}_{0.05}(4,12)=2.48$, & $\mathrm{F}_{0.01}(4,12)=5.41$
\end{tabular}

$S S_{j}$ is sum of squares of deviation; $d f_{j}$ is degree of freedom; $V_{j}$ is mean square; $F_{j}$ is $F$-test value for factors; $e(\mu)$ is error.

In order to acquire the significant factors more accurately, analysis of variance (ANOVA) method was also used. The results of ANOVA are given in Table 4, and the $F$ values of various factors are obtained and shown in Table 4. And then, by evaluating $F$ values, the significant levels are acquired and described in descending order as “***", “**" and "**". Eventually, considering the results of range analysis and ANOVA comprehensively, three factors exert great influence on the $\mathrm{CoF}$, including normal load, while sliding velocity and temperature show less effect on the CoF.

\section{Effect of normal load on friction behaviour}

Figure 2(a) shows that there is a peak in the curve of CoF with the increasing normal load. The results had the same trend in M. A. Jun and H. Yang's [10]. As can be seen from the Figure 2(b), the area of high $\mathrm{CoF}$ is concentrated in the zone with high temperature and low sliding velocity, the normal load is smaller in the meantime. The analysis shows that CoF increases when the normal 
load is lower than the critical load value. The reason is that increasing pressure enhances the mechanical interlocking effect between Ti-6Al-4V alloy and die steel [11]. When the normal load is large enough, the friction type between the friction pair is changed with the increase of normal stress. The decreasing trend of $\mathrm{CoF}$ may relate to the softening of frictional materials with the obvious furrow. On the one hand, dry friction is transformed into viscous friction. The friction resistance decreases. So $\mathrm{CoF}$ decreases and then tends to be stable. Simultaneously, when the normal load reaches a certain value, the pressure helps to restrain surfaces from roughening and improve the lubrication condition between Ti-6Al-4V alloy and die steel, thus leading to a minor $\mathrm{CoF}[11,12]$.

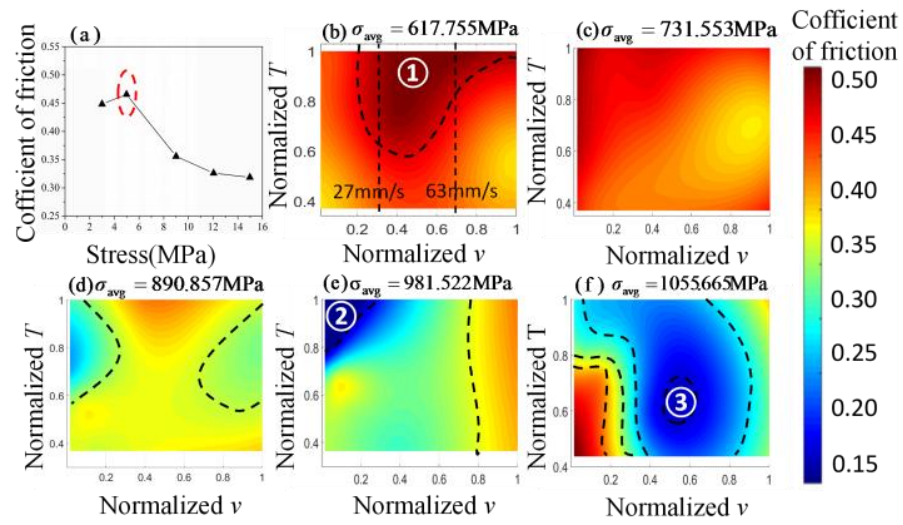

Figure 2. The orthogonal result and ODF on stress (Tavg: $339.7-889.5 \mathrm{~K} ; v_{\text {avg: }}: 14.137-900 \mathrm{~mm} / \mathrm{s}$ ).

Changes of most area with approximate $\mathrm{CoF}$ in each ODF has the same trend in Figure 2(a). It is obvious that the high $\mathrm{CoF}$ region(1) in Figure 2 is changed to the low CoF region(2)(3). In Figure 2(f), when the normal load is large, CoF is very sensitive to the sliding velocity in a longitudinal direction. Such result is consistent with the results of the orthogonal test. Therefore, when the normal load is relatively high in materials process industry, the friction and lubrication condition between Ti-6Al-4V alloy and die can be improved by adjusting the deformation rate.

\section{Effect of sliding velocity on friction behaviour}

Figure 3(a) illustrates that when sliding velocity is comparatively low-level, CoF rises as sliding velocity increases. With the sliding velocity increasing, elastic-plastic deformation and oxide layer attachment turn up and intensify. Then surface occlusion is strengthened, leading to increasing of $\mathrm{CoF}[10]$. However, high sliding velocity also weakens the adhesion between surface micro-bulge and contact surface, decreasing CoF and offsetting the former increase substantially. So there would be a critical value of sliding velocity $\left(v_{c}\right)$ [13]. In this test, when sliding velocity surpasses 200 $\mathrm{mm} / \mathrm{s}$, the later effect takes dominant position and CoF tends to decrease from increasing as the sliding velocity rises.
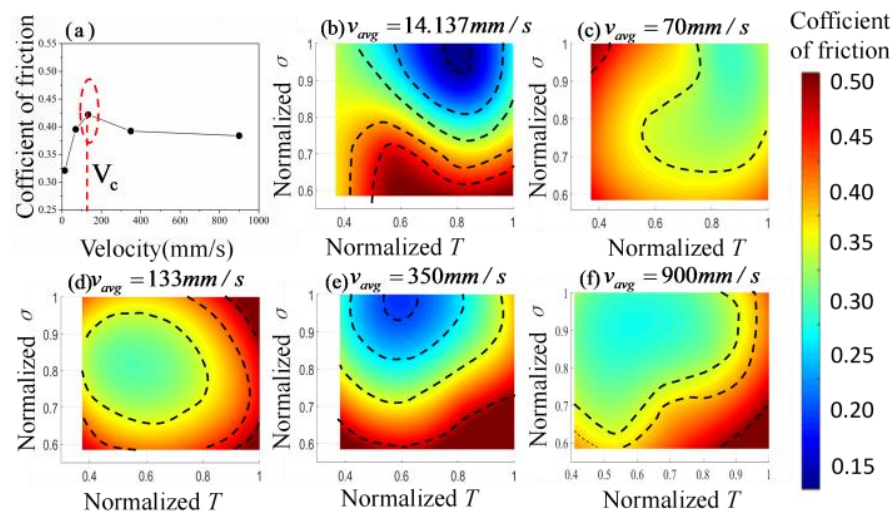

Figure 3. The orthogonal result and ODF on velocity ( $T_{\text {avg: }}$ 339.7-889.5 K; $\sigma_{\text {avg: }}$ 617.7551055.665 MPa). 
From the discussion of orthogonal friction test, we know that normal load has intensive effect, which is illustrated considerably in Figure 3(a). As it shows, higher $\mathrm{CoF}$ appears when the level of normal load is relatively low. However, when normal load reaches a high value, micro-bulges crack and are ground to tiny particles. These tiny particles reduce resistance and have the effect of decreasing CoF. For Figure 3(c), (d) and (e), when sliding velocity ranges from 133 to $900 \mathrm{~mm} / \mathrm{s}$, the contour lines of $\mathrm{CoF}$ are approximately a circle, which means the effects of normal load and temperature are similar under these conditions. And this is the result of coupling and interaction for the two factors.

\section{Effect of temperature on friction behaviour}

Figure 4(a) shows that $\mathrm{CoF}$ increases with the increase of temperature when temperature is below $623.2 \mathrm{~K}$. Some studies show that adhesive and abrasive wear accompanied by a small amount of fatigue wear dominate at low temperature. The content of oxygen element on the surface gradually increases with increasing temperature. Then oxide film on the alloy surface is formed continuously. At low temperature, the elevated temperature causes thickening of the surface oxide film and increasing adsorption force between the molecules [14], resulting in a slight increase in CoF. Most studies show that there is always a temperature range in which $\mathrm{CoF}$ decreases with temperature increasing. The decrease of $\mathrm{CoF}$ with the increase of temperature, may be because the formation of more oxides reduces the adhesion between friction pairs, which can be illustrated in the report of EDS [15]. When the temperature is higher than $723.2 \mathrm{~K}$, CoF increases again as the result of the occurrence of shear friction mechanism. The friction force includes adhesion force and deformation force. The harder one ploughed a trench on the relative softer one during the process of sliding. The substrate material is crushed and accumulated in the groove. The deformation of surface consumes energy. Cutting plough friction shows up, so CoF increases.

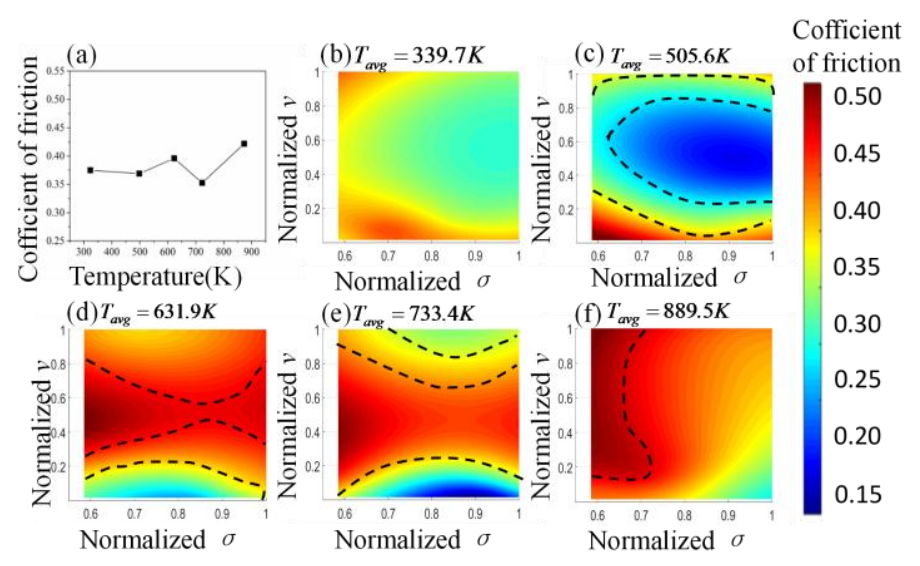

Figure 4. The orthogonal result and ODF on temperature $\left(v_{\text {avg: }}: 14.137-900 \mathrm{~mm} / \mathrm{s} ; \sigma_{\text {avg }}: 617.755-\right.$ $1055.665 \mathrm{MPa})$

Figure 4(c), (d) and (e) shows that, during the friction process under average temperature of $505.6 \mathrm{~K}, 631.9 \mathrm{~K}$ and $733.4 \mathrm{~K}$ respectively, the distribution of $\mathrm{CoF}$ is along the longitudinal axis, in another word, is parallel to sliding velocity. This phenomenon shows that the change of CoF is more sensitive to the sliding velocity in the temperature range of $505.6 \mathrm{~K}$ to $733.4 \mathrm{~K}$. Therefore the friction condition between Ti-6Al-4V alloy and die steel can be improved by adjusting the sliding velocity such as the machining speed in materials process industry, when the deformation temperature is in this confined range. The state of friction surface is different under changing sliding velocity, and leads to the different CoF. Figure 4(c) to (f) shows the effect of sliding velocity on the CoF. With temperature increasing, sliding velocity has a marked effect firstly and then decreases. The area of high CoF also expands firstly and shrinks then. This principle is consistent with the separate analysis about sliding velocity. The distribution of $\mathrm{CoF}$ at high temperature is approximately parallel to the sliding velocity axis. Meanwhile normal load is concentrated in the 
lower region. Figure 4(f) shows that normal stress has great influence on the CoF under $889.5 \mathrm{~K}$. The distribution of high $\mathrm{CoF}$ is in low normal load area. Such distribution corresponds to the orthogonal analysis about normal load. Therefore, the friction condition between Ti-6Al-4V alloy and die can be improved by adjusting normal load when the temperature is higher than $889.5 \mathrm{~K}$ in materials process industry.

\section{Worn-out appearances and friction mechanism analysis}

Figure 5 illustrates the worn-appearances of samples under $429 \mathrm{~K}, 722 \mathrm{~K}$ and $872 \mathrm{~K}$ respectively. The size of abrasive particles and appearances of worn-out surface reflect the changes of friction mechanism. For the sample under temperature $429 \mathrm{~K}$, normal load $5 \mathrm{~N}$ and sliding velocity 133 $\mathrm{mm} / \mathrm{s}$, as showed in Figure 5(a), normal stress is lower than yield strength of Ti-6Al-4V alloy. There is no obvious deformation and this process can be explained by dry friction mechanism. Small quantities of abrasive dust, spreading on the worn surface, reduce the friction resistance through gathering and rolling.
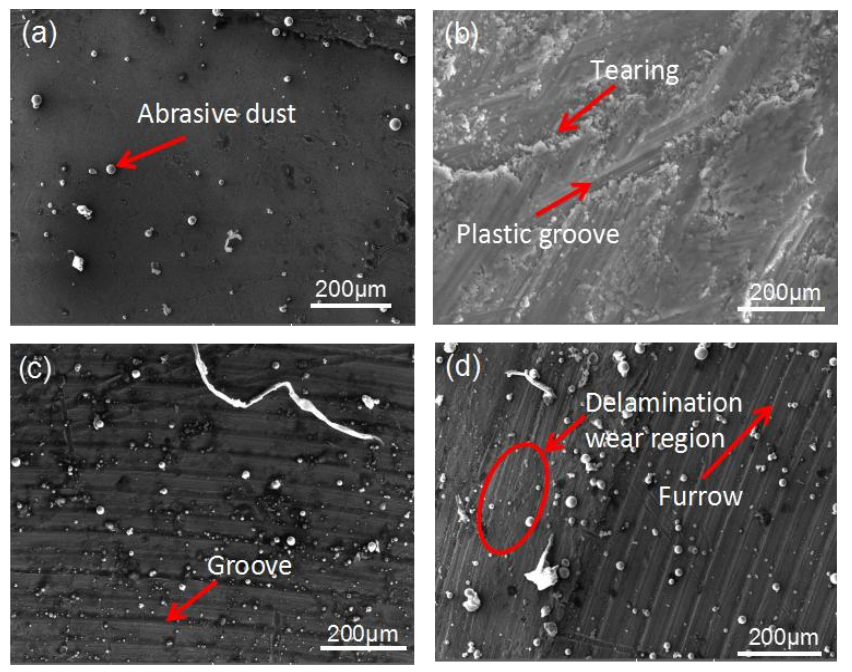

Figure 5. SEM of Ti-6Al-4V alloy after grinding: (a) $T=497.2 \mathrm{~K}, P=5.0 \mathrm{~N}, v=133.00 \mathrm{~mm} / \mathrm{s}$; (b) $T=623.2 \mathrm{~K}, P=9.0 \mathrm{~N}, v=14.137 \mathrm{~mm} / \mathrm{s}$; (c) $T=722.2 \mathrm{~K}, P=9.0 \mathrm{~N}, v=900.00 \mathrm{~mm} / \mathrm{s}$; (d) $T=872.2 \mathrm{~K}$, $P=12.0 \mathrm{~N}, v=900.00 \mathrm{~mm} / \mathrm{s}$.
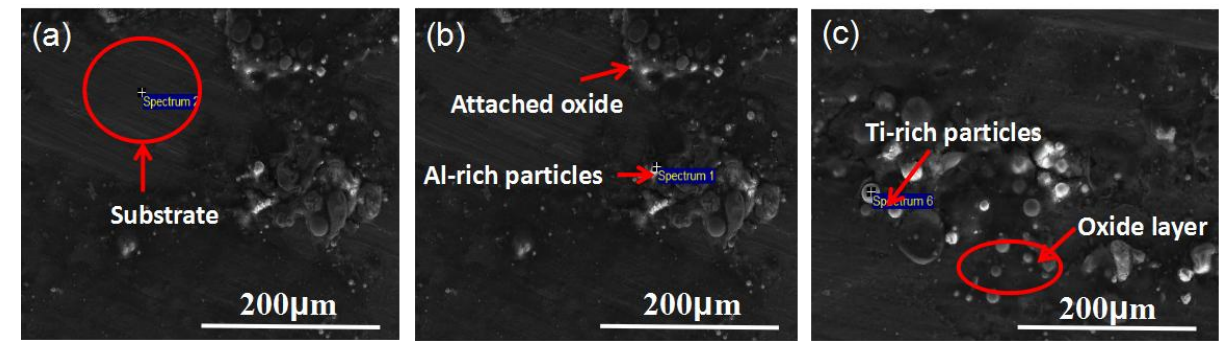

Figure 6. EDS of worn-out surfaces on Ti-6Al-4V alloy after grinding ( $T=623 \mathrm{~K}, P=9 \mathrm{~N}, v=14.137$ $\mathrm{mm} / \mathrm{s}$ ): (a) matrix; (b) Ti enriched particles; (c) Al enriched particles.

Taking unavoidable residual atmosphere in high temperature friction and wear testing equipment into account, we choose to analyse substance components of the sample's worn-out surface under temperature $623 \mathrm{~K}$, normal load $9 \mathrm{~N}$ and sliding velocity $14.137 \mathrm{~mm} / \mathrm{s}$. From Figure 6, we found that substrate of worn-out surface is still titanium alloy, while some abrasive dust desquamated and adhesion points are titanium oxides or iron oxides. As showed in Figure 5(b), the worn-out surface with obvious plastic ploughing and slight adhesion emerges. The reason is continuous shearing between micro-bulges and contact surface inducing the fracture of bulges. Since desquamation area is relatively large, spalled surface and materials tend to be oxidized. After reduplicative deformation and squeezing, island-appearance oxide tends to form on the worn-out surface. At first, oxide layer 
contributes to protecting base alloy and decreases CoF. While with the normal load and temperature increasing, the material is spalled, cracked and ground into small particles, which is shown as oxidation wear. So, the process includes abrasive wear and adhesive wear, accompanying with oxidation wear.

Figure 5(c) is the SEM photograph of the sample under temperature $722 \mathrm{~K}$, normal load $9 \mathrm{~N}$ and sliding velocity $900 \mathrm{~mm} / \mathrm{s}$. The worn-out surface has more abrasive dust and clearer ploughing, and the abrasive dust assembles on the surface. These appearance means typical ploughing wearing. According to above discussion, there still is oxidation wear under this situation. As to higher temperature, $872 \mathrm{~K}$, Ti-6Al-4V alloy softens gradually, and is easily deformed [16], as Figure 5(d) shows. Increasing load at the same time makes more abrasive dust and more severe ploughing. When a ploughing forms, materials transfer to two sides and become ridge margin, after which these spinal bulges are flatten again. These reduplicative loading and unloading processes cause deformation and micro-cracks extension [16]. When micro-crack reaches a critical size, large scale materials spall from base surface. This situation is severe wear mechanism (fatigue and delaminating wear). The wear process tends more and more severe with the change of the three parameters, as Figure 7 showed.

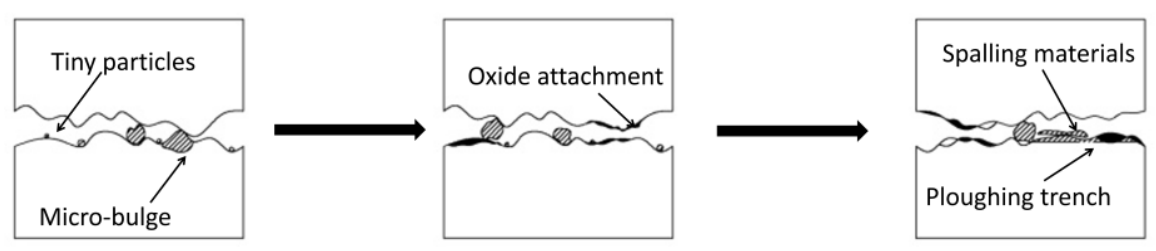

Figure 7. Schematic diagram of mechanism transition during friction and wear.

\section{Conclusions}

Friction behaviour and mechanism is very complex with the influence of friction temperature, normal load and sliding velocity. The significance of three factors for $\mathrm{CoF}$ is conducted by orthogonal experiments. The qualitative description of friction behaviour is studied. Following conclusions are achieved:

(1) The significant factors of CoF in Ti-6Al-4V alloy analyzed by the orthogonal experiments are determined as normal load > sliding velocity $>$ temperature.

(2) With increasing normal load or sliding velocity, $\mathrm{CoF}$ increases firstly and then decreases. With temperature increasing, CoF rises firstly and then falls, finally it decreases again. Under some specific conditions, $\mathrm{CoF}$ will be very sensitive to a certain factor in the ODF. It's helpful to guide the adjustment of the friction state between friction pairs during the hot-working in materials process industry.

(3) Friction appearances and microstructures reflect the transformation of friction mechanism. The dry friction mechanism is more obvious in the lower temperature and normal load. With the increase number of severe ploughing appears, the friction and wear mechanism transforms into severe wear and friction i.e., from abrasive wear, oxide wear and adhesive wear finally into fatigue wear and spalling wear.

\section{Acknowledgement}

The authors are very grateful for the support received from the National College Students Innovation Experiment Program (Grant No. 201510699063).

\section{References}

[1] K. P. Rao, K. Sivaram. J. Mater. Process. Technol. 37, 295-318 (1993).

[2] D. W. Zhang, H. Yang. Int J Adv Manuf Technol 68, 1339-1350 (2013). 
[3] P. L. Menezes, K. Kumar, Kishore, SV Kailas. Int J Adv Manuf Technol 40,1067-1076 (2009).

[4] M. F. Ashby, S. C. Lim. Scripta Metallurgica et Materialia, 24, 805-810 (1990).

[5] A. Molinari, Y. Estrin, S. Mercier. J Tribol 121, 35-41 (1999).

[6] P. J. Blau. Friction Science \& Technology (Marcel Dekker Inc, New York, Hong Kong,1996).

[7] H. L. Xing, P. Mora, A. Makinouchi. Philos. Mag. A 57, 727-730 (2006).

[8] Garcia, Claudio. Control Eng Pract 16, 1231-1243 (2008).

[9] X. H. Cui, Y. S. Mao, M. X. Wei, S. Q. Wang. Tribol T 55, 542(2012).

[10] M. Jun, H. Yang, L. Heng, D. Wang, G. J. LI, Trans. Nonferrous Met. Soc. China 25, 2924$2931(2015)$.

[11] E. D. Szakaly, J. G. Lenard. J. Mater. Process. Technol 210, 868-876 (2010).

[12] A. Azushimaa, M. Sakuramotoa. CIRP Ann-Manuf Techn 55, 303-306 (2006).

[13] M. D. Sharma, R. Sehgal. Ind Lubr Tribol 66, 174-183 (2014).

[14] J. G. Lenard, S. Kalpakjian. CIRP Ann-Manuf Techn 40, 223-226 (1991).

[15] J. Hardell, B. Prakash. Tribol Int 41, 663-671 (2008).

[16] X. F. Yao, F. Q. Xie, Y. Han. Rare Meetal Mat Eng 41, 1463-1466 (2012). 